\title{
Blurring the boundary
}

\author{
Where science and technology aren't far apart
}

Nature combined many forces to engineer and produce the manifest universe. Man has sought to understand these forces and their interplay to explain and manipulate the world around us. The drive to do this has been provided not only by innate human curiosity to explore and discover truth and its beauty but also by the need to improve our well-being. We tend to call the understanding of nature "science ...." and the application of scientific or empirical knowledge "technology". This compartmentalization into science and technology has served us well and will probably continue to do so in the future.

There are, however, a few very broad areas of technical endeavor where such a division is at best blurred and here scientific knowledge is almost immediately translated to technological know-how, and where technology poses

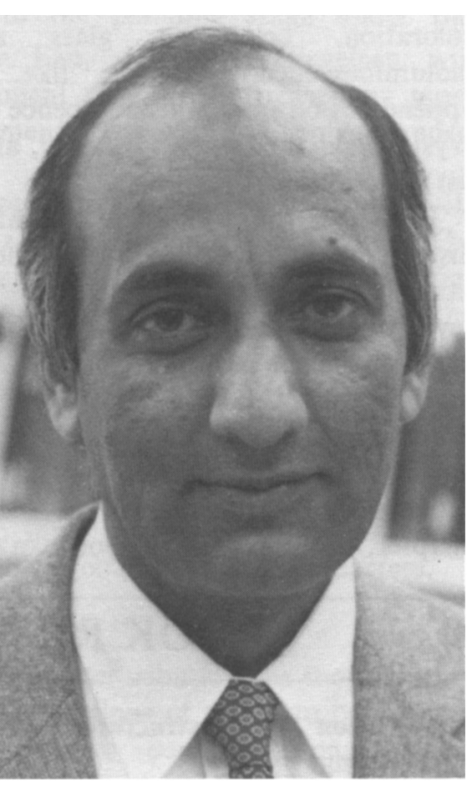

PRAVEEN CHAUDHARI questions that science cannot as yet answer. This ferment, which is rich both in intellectual content and potential for application, is characteristic of research relating to high technology. As such, it affects the quality of life and the economic power of each nation directly.

Two examples that come to mind are research in materials and medicine. Whereas it is easy to relate to the need for placing resources in medicine - we can all personally relate to pain, disease and mortality - our appreciation for the need for materials research requires some reflection. Consider, for example, computers and telecommunications, as a single interwoven industry. Their ubiquitous presence and vital role in our society are undeniable. Their economic role -together they will be a trillion-dollar business by the end of this decade- in world affairs can hardly be ignored. Even though the industry has been characterized by spectacular progress, it is evident that continuing progress in hardware will almost completely depend on our ability to control the properties of materials.

This hardware, such as the transistor on a VLSI chip or the macroscopic package used for housing these chips, is built by the addition or removal of appropriate materials in well defined geometrical and spatial arrangements. Complexity in manufacturing VLSI devices is almost entirely associated with the shrinking of the physical size of materials -from micron to submicron dimensions. Knowledge about the properties of metals, polymers, ceramics, semiconductors, insulators, and their composites in restricted dimensions is required. Knowledge about interfaces between these materials is necessary. Knowledge about the microscopic mechanisms of growth or removal of atoms or molecules from surfaces is essential for developing alternate processing technologies. These are only a few general observations. The list describing areas where scientific knowledge is needed is long. It is my belief that the lead in hardware could go to those that can best marshal their resources in materials sciences.

Yet at our universities' research in materials related to the

\section{The lead in hardware \\ Could go to those who best \\ Marshal their resources in materials science}

electronics industry is far from adequate. There are many factors responsible for this, among them that industry has not effectively communicated its needs, that research in this area can be expensive and that help from industry or government is inadequate to nucleate a number of new activities without proper equipment and infrastructure. However, given the unusual interdisciplinary and science-technology character of materials research, the nation's universities, industrial laboratories and funding agencies need to work together so that the multifaceted expertise of our university research establishment can be brought to bear in this important area, both to generate new information and train experts. This cooperative effort must take place, not only to assure industry's lead in tomorrow's technology and the well-being of the nation, but, more fundamentally, to assure that future work in materials research by scientists and technologists will proceed in natural harmony and on a self-sustaining basis.

Praveen Chaudhari

Yorktown Heights, NY

Praveen Chaudhari is Vice President and Director of Research.at IBM's T. J. Watson Research Center in Yorktown Heights, New York. This editorial is also scheduled to be published in the October 1984 issue of Physics Today. 